\title{
Patterns of diagnostic procedures for lung cancer pathology in the Middle East and North Africa
}

\begin{abstract}
Abdul Rahman Jazieh ${ }^{1,2,3}$, Adda Bounedjar ${ }^{4}$, Foad Al Dayel ${ }^{5}$, Shamayel Fahem ${ }^{5}$, Arafat Tfayli ${ }^{6}$, Kakil Rasul ${ }^{7}$, Hassan Jaafar ${ }^{8}$, Mohammad Jaloudi ${ }^{8}$, Turki Al Fayea ${ }^{9}$, Hatim Q. Almaghrabi ${ }^{9}$, Hanaa Bamefleh ${ }^{1,2,10}$, Khaled AlKattan ${ }^{5,11}$, Blaha Larbaoui ${ }^{12}$, Taha Filalli ${ }^{13}$, Mufid Al Mistiri ${ }^{7}$, Hamed Alhusaini ${ }^{5}$

${ }^{1}$ King Abdullah International Medical Research Center, Riyadh, Saudi Arabia; ${ }^{2}$ College of Medicine, King Saud Bin Abdulaziz University for Health Sciences, Riyadh, Saudi Arabia; ${ }^{3}$ Department of Oncology, Ministry of National Guard Health Affairs, Riyadh, Saudi Arabia; ${ }^{4}$ Department of Medical Oncology, Blida I, Algeria; ${ }^{5}$ King Faisal Specialist Hospital and Research Center, Riyadh, Saudi Arabia; ${ }^{6}$ American University of Beirut, Beirut, Lebanon; ${ }^{7}$ Weill Cornell Medical College, Doha, Qatar; ${ }^{8}$ Tawam Hospital, Al-Ain, United Arab Emirates; ${ }^{9}$ Princess Noorah Oncology Center, Ministry of National Guard Health Affairs, Jeddah, Saudi Arabia; ${ }^{10}$ Department of Pathology and Laboratory Medicine, Ministry of National Guard Health Affairs, Riyadh, Saudi Arabia; ${ }^{11}$ College of Medicine, Alfaisal University, Riyadh, Saudi Arabia; ${ }^{12}$ Department of Medical Oncology, Anti Cancer Center, Oran, Algeria; ${ }^{13}$ Department of Medical Oncology, CHU Constantine, Algeria

Contributions: (I) Conception and design: AR Jazieh; (II) Administrative support: AR Jazieh; (III) Provision of study materials or patients: All authors; (IV) Collection and assembly of data: AR Jazieh; (V) Data analysis and interpretation: AR Jazieh; (VI) Manuscript writing: All authors; (VII) Final approval of manuscript: All authors.

Correspondence to: Abdul Rahman Jazieh, MD, MPH. Chairman, Department of Oncology King Abdulaziz Medical City, P.O. Box 22490, Riyadh 11426, Saudi Arabia. Email: jaziehoncology@gmail.com.
\end{abstract}

Background: Accurate pathological diagnosis is the first critical step in the management of lung cancer. This step is important to determine the histological subtype of the cancer and to identify any actionable targets. Our study aimed at evaluating the patterns of procedures used to obtain pathological diagnosis of lung cancer in the Middle East and North Africa (MENA) Region.

Methods: Data of consecutive patients with the diagnosis of non-small cell lung cancer (NSCLC) were collected from participating centers from different countries in the MENA Region. Methods of obtaining tissue diagnosis and workup were analyzed to determine the practice patterns of obtaining tissue diagnosis of lung cancer.

Results: A total of 566 patients were recruited from 10 centers in 5 countries including Saudi Arabia, United Arab Emirates (UAE), Qatar, Lebanon and Algeria. Majority of patients were males (78.1\%) with a median age of 61 years (range, 22-89 years). Obtaining tissue diagnosis was successful in the first attempt in $72.3 \%$ of patients, while $16.4 \%$ and $6.3 \%$ of patients required $2^{\text {nd }}$ and $3^{\text {rd }}$ attempt, respectively. The success in first attempt was as follows: image guided biopsy (91\%), surgical biopsy (88\%), endobronchial biopsy (79\%) and cytology (30\%). The success in the second attempt was as follows; surgical biopsy (100\%), image guided biopsy (95\%), endobronchial biopsy (65\%), cytology (25\%).

Conclusions: More than quarter of the patients required repeated biopsy in the MENA Region. Image guided biopsy has the highest initial yield. Implementing clear process and multidisciplinary guidelines about the selection of diagnostic procedures is needed.

Keywords: Lung cancer; pathology; diagnostic procedures; work-up

Submitted Jul 08, 2019. Accepted for publication Nov 19, 2019.

doi: $10.21037 /$ jtd.2019.12.03

View this article at: http://dx.doi.org/10.21037/jtd.2019.12.03

(c) Journal of Thoracic Disease. All rights reserved. 


\section{Introduction}

Lung cancer is the leading cause of cancer death in the world. In the Middle East and North Africa (MENA) region, lung cancer is a major health problem and ranked in the top cancer sites in many countries in the region $(1,2)$.

Establishing accurate pathological diagnosis is the first step of the proper management of lung cancer. This diagnosis is important for the disease management especially the selection of systemic therapy in the metastatic setting.

Knowing the histology subtype of non-small cell lung cancer is still relevant and the first step to avoid harmful treatment, such as the use of bevacizumab in squamous cell cancer, or the use of less effective treatment, such as pemetrexed in squamous histology subtype (3). This requires performing immunohistochemistry for markers to differentiate squamous form non-squamous (TTF, Napsin, P63) (4).

Furthermore, each major subtype of lung cancer harbors different actionable mutations with most of them present in non-squamous histology. This will dictate further laboratory workup based on prevailing practice (5). Staining for PDL1 has become recently a requirement to determine if the patient is candidate for first line immune therapy treatment (6). Another important utilization of the biopsy in the early phase of the patient management is staging by documenting the involvement of lymph node or an organ that may upstage the disease.

In summary, the biopsy must be adequate by having enough tissue material to discern the subtype of lung cancer and enable performing molecular studies to identify actionable targets. Therefore, selecting the type of the procedure to obtain the initial biopsy is critical to confirm diagnosis early on and avoid repeating biopsy with increasing risk of complications and delay of treatment initiation. Many procedures that are commonly used in diagnosing lung cancer includes: fiberoptic bronchoscopy with or without transbronchial needle aspiration (TBNA), endobronchial ultrasonography (EBUS), image guided transthoracic needle aspiration, mediastinoscopy, pleural fluid analysis (thoracentesis) and thoracoscopy, and surgical approaches (7).

The selection of the procedure depends on the patient condition, disease status and available expertise and equipment (8). Nevertheless, whatever is the approach used, if the biopsy is not adequate as mentioned earlier, repeating the biopsy will be indicated using similar or different approach. Therefore, the team managing lung cancer patients at the diagnosis phase should be familiar with the yield of each technique and associated risks-benefits.

In this manuscript, we are reporting the initial work-up approaches to obtain tissue diagnosis for lung cancer in the Middle East and North Africa Region.

\section{Methods}

\section{Study design}

Data of consecutive patients with non-small cell lung cancer were collected retrospectively from participating centers in different countries in the MENA Region. Methods of obtaining tissue and workup were analyzed to determine the yield of each methods and challenges encountered.

Ten centers from 5 countries participated in the study namely: Saudi Arabia (3 centers), United Arab Emirates (1 center), Qatar (1 center), Lebanon (1 center) and Algeria (4 centers).

\section{Sample size}

All consecutive NSCLC cases during the study period of January 2013 to January 2014 were included.

Ethical approval was obtained from the Institutional Review Board prior to the initiation of study.

\section{Data acquired}

A paper Clinical Research Form (CRF) was used to obtain the following data: demographic information such as age, gender, and ethnicity; information about procedures used to obtain biopsy, number of attempts, site of biopsy; information about the disease such as subtype and stage. Data were entered into excel file database then used for statistical analysis.

\section{Statistical analysis}

SAS v9.2 (SAS Institute, NC, USA) was used for statistical analysis.

Patient and disease characteristics, type of procedures were calculated as counts and proportion for categorical variables and continuous variables were reported as a mean and standard deviation. Percentage of patients who underwent one, two and three or more attempts were calculated with type of procedures. Chi-square tests used to 
Table 1 Patients characteristics $(\mathrm{N}=566)$

\begin{tabular}{|c|c|}
\hline Characteristics & Value \\
\hline Age (years), median [range] & 61 [22-89] \\
\hline \multicolumn{2}{|l|}{ Gender, n (\%) } \\
\hline Male & 442 (78.09) \\
\hline Female & $114(20.14)$ \\
\hline Missing & $10(1.77)$ \\
\hline \multicolumn{2}{|l|}{ Smoking } \\
\hline Current & $170(30.04)$ \\
\hline Former & $113(19.96)$ \\
\hline Never & $99(17.49)$ \\
\hline Missing/unknown & $184(32.51)$ \\
\hline \multicolumn{2}{|l|}{ Nationality } \\
\hline Algerian & $306(54.06)$ \\
\hline Saudi & $118(20.85)$ \\
\hline Lebanese & $43(7.60)$ \\
\hline Emirati & $19(3.36)$ \\
\hline Qataris & $9(1.59)$ \\
\hline Others ${ }^{*}$ & $37(6.54)$ \\
\hline Missing & $34(6.01)$ \\
\hline \multicolumn{2}{|l|}{ Number of attempts } \\
\hline One attempt & 409 (72.26) \\
\hline Two attempts & $92(16.25)$ \\
\hline Three attempts and more & $36(6.36)$ \\
\hline Missing & $29(5.12)$ \\
\hline \multicolumn{2}{|l|}{ Site of first biopsy } \\
\hline Lung & 468 (82.69) \\
\hline Pleura & $23(4.06)$ \\
\hline Brain & $6(1.06)$ \\
\hline Bone & $8(1.41)$ \\
\hline Liver & $4(0.71)$ \\
\hline Other** & $30(5.30)$ \\
\hline Missing & $27(4.77)$ \\
\hline
\end{tabular}

*, others include: Pakistani, Pilipino, Indian, American, and British; **, others include lymph node, supraclavicular LN, mediastinal LN, spine, skin, hepatic mass and adrenal gland. evaluate any correlation between certain demographic and clinical features and the number of biopsy attempts.

\section{Results}

566 patients were included in the study, majority were males $(78.09 \%)$ with a median age of 61 years (range, 2289 years) (Table 1). Majority of the cases were diagnosed with first attempt (72.26\%), however, $16.25 \%$ required two attempts and $6.36 \%$ required three or more attempts. Lung was the most common site for first biopsy (Table 1).

Data on methods of obtaining tissue and the yield in each attempt is depicted in Table 2.

The success in first attempt was attained in $72 \%$ of the patients as follows: image guided core biopsy (91\%), surgical biopsy (88\%), endobronchial biopsy (79\%), and cytology $(30 \%)$. The success in second attempt was as follows: surgical biopsy (100\%), image guided core biopsy (95\%), endobronchial biopsy (65\%), cytology (55\%) (Table 2).

Stage IV $(27.1 \%$ vs. $13.0 \%$ in stage I to III, $\mathrm{P}=0.003)$ was the only predictor of increasing number of attempts in univariate analysis (Table 3).

\section{Discussion}

Our study showed that majority of lung cancer cases are diagnosed from the first attempt, but fraction of the patient requires repeated attempt of biopsy using different approaches. The best yield is with image guided biopsy and the least is in cytology which consistent with the literature (9). The yield of our initial biopsy was similar to the reports in the literature with repeat rate varies based on the procedures used (10-13).

The need to repeat the biopsy was more common in stage 4 than earlier stages which can be due to the use of better diagnostic approached such as image guided biopsy or surgery in earlier stages and the use of cytology in the advanced stages.

There are different approaches to improve the yield of the biopsy and avoid delay in diagnoses and increase risk of complications (Table 4). Involvement of multidisciplinary team (MDT) in the decision making to choose the best approach and site of biopsy is a must nowadays. The team should include interventional radiologist, interventional pulmonologist or gastroenterologist to be able to access hard to reach lesions or lymph nodes. The team should 
Table 2 Type of procedures performed at each attempt

\begin{tabular}{|c|c|c|c|c|c|}
\hline Procedure & $\begin{array}{l}1^{\text {st }} \text { attempt } \\
(n=566)\end{array}$ & $\begin{array}{l}\text { Required } 2^{\text {nd }} \\
\text { attempt }\end{array}$ & Type of specimen & Required $3^{\text {rd }}$ attempt & Type of specimen \\
\hline \multirow[t]{3}{*}{ Cytology } & \multirow[t]{3}{*}{$89(15.7 \%)$} & \multirow[t]{3}{*}{$\begin{array}{l}\text { Yes } 62(70 \%) \\
\text { no } 27(30 \%)\end{array}$} & Cytology: 19 (31\%) & Yes: 7 (37\%); no: 12 (63\%) & $\begin{array}{l}\text { Cytology } 3(42 \%) \text {; image } 2(29 \%) \text {; } \\
\text { surgical } 2(29 \%)\end{array}$ \\
\hline & & & Endobronchial: 26 (42\%) & Yes: 12 (46\%); no: 14 (54\%) & $\begin{array}{l}\text { Cytology } 6(50 \%) \text {; image } 5 \text { (42\%); } \\
\text { surgical } 1(8 \%)\end{array}$ \\
\hline & & & Surgical: $0(0 \%)$ & & \\
\hline \multirow{3}{*}{$\begin{array}{l}\text { Endobronchial } \\
\text { biopsy }\end{array}$} & \multirow[t]{3}{*}{$173(30.6 \%)$} & \multirow{3}{*}{$\begin{array}{l}\text { Yes: } 36(21 \%) \\
\text { no: } 137(79 \%)\end{array}$} & Cytology: 11 (28\%) & Yes: 7 (64\%); no: 4 (36\%) & \multirow[t]{2}{*}{ Cytology 3 (43\%); image 4 (57\%) } \\
\hline & & & Endobronchial: 2 (6\%) & Yes: 0 (0\%); no: 2 (100\%) & \\
\hline & & & Image: 14 (39\%) & Yes: 2 (14\%); no: 12 (86\%) & Surgical 2 (100\%) \\
\hline \multirow{3}{*}{$\begin{array}{l}\text { Image guided } \\
\text { core biopsy }\end{array}$} & \multirow{3}{*}{$197(34.8 \%)$} & \multirow{3}{*}{$\begin{array}{l}\text { Yes: } 17(9 \%) \\
\text { no: } 180(91 \%)\end{array}$} & Endobronchial: 5 (29\%) & Yes: 0 (0\%); no: 5 (100\%) & \\
\hline & & & Image 4 (29\%) & Yes: 2 (50\%); no: 2 (50\%) & Image 2 (100\%) \\
\hline & & & Surgical 5 (29\%) & Yes: 0 (0\%); no: 5 (100\%) & \\
\hline \multirow[t]{4}{*}{ Surgical Biopsy } & \multirow[t]{4}{*}{$100(17.7 \%)$} & \multirow{4}{*}{$\begin{array}{l}\text { Yes: } 12(12 \%) \\
\text { no: } 88(88 \%)\end{array}$} & Cytology 6 (50\%) & Yes: 3 (50\%); no: 3 (50\%) & Cytology: 3 (100\%) \\
\hline & & & Endobronchial: 4 (33\%) & Yes: 1 (25\%); no: 3 (75\%) & Cytology: 1 (100\%) \\
\hline & & & Image: 2 (17\%) & Yes: 0 (0\%); no: 2 (100\%) & \\
\hline & & & Surgical: $0(0 \%)$ & 0 & \\
\hline
\end{tabular}

select the procedure based on the highest possible yield balanced with associated risk (14). Our study did not evaluate the involvement of MDT in the decision making. It is known that multidisciplinary team approaches need to be enhanced in our region to improve patient care (15-17).

Our study did not evaluate definite reason for the inadequate biopsy and how the decision was made in the first place to select the procedure, but we recommend each center to perform root cause analysis for failures and implement intervention to reduce the rate of re-biopsy. This should be part of quality assurance plan for the whole process. Table 4 highlights some of these approaches. Incorporating these approaches into practice may require resources and expertise to be addressed individually as onesize-fits-all recommendations will not work.

Other methods to enhance the yield of the biopsy is implementing evidence-based guidelines adapted to the local setting (18).

The use of PET scan may help identify the active disease from collapsed normal lung tissue or benign lesions, or may detect more accessible lesion that was not described with other imaging modalities (19-21).

As reported earlier on our study population, molecular studies were not performed due to inadequate specimen in $11.6 \%$ of the patients (22). Therefore, having a tissue management plan and use the more advanced techniques such as NextGen Sequencing (NGS) will help conserve tissue from small specimens (23). After confirming diagnosis of lung cancer, molecular studies can be done on liquid biopsy and avoid the need of re-biopsy in certain cases (24).

Having Rapid On-Site-Evaluation (ROSE) will determine at procedure site if adequate tissue is obtained to avoid redoing the biopsy $(25,26)$.

\section{Conclusions}

In conclusion, selecting the initial procedure to obtain tissue diagnosis should be done carefully and proper pathological workup should minimize the need for exposing the patients for re-biopsy. 
Table 3 Demographic and clinical characteristics in relation to the number of biopsy attempts

\begin{tabular}{|c|c|c|c|c|}
\hline Characteristics & Overall & One attempt & Two attempts or more & $P$ value \\
\hline Male & $442(79.5)$ & $329(77.8)$ & $94(22.2)$ & \\
\hline Female & $114(20.5)$ & $75(70.8)$ & $31(29.2)$ & \\
\hline Overall stage & & & & $0.003^{\star}$ \\
\hline IV & $370(76.6)$ & 256 (72.9) & $95(27.1)$ & \\
\hline Regions & & & & 0.960 \\
\hline Gulf & $146(27.8)$ & $107(75.4)$ & $35(24.6)$ & \\
\hline Non-gulf & $380(72.2)$ & $272(75.1)$ & $90(24.9)$ & \\
\hline Site from which biopsy was taken & & & & 0.111 \\
\hline Lung & $468(82.7)$ & $343(76.9)$ & $103(23.1)$ & \\
\hline Others & $71(12.5)$ & $45(68.2)$ & $21(31.8)$ & \\
\hline
\end{tabular}

${ }^{*}$, the Chi-square statistic is significant at the 0.05 level.

Table 4 Approaches to enhance the yield of the biopsy and reduce the need for repeated biopsy

\begin{tabular}{ll}
\hline Approach & Benefits \\
\hline Multidisciplinary team discussion & Determine best procedure and lesion to be taken \\
Adapt clinical practice guidelines & To create standard approach for common scenarios \\
Use of PET scan & Identify the best accessible active lesion \\
Tissue management plan & Proper utilization of specimen and efficient processing to minimize the use of tissue for IHC \\
Use of next gene sequencing & To conserve tissue especially with small specimens \\
Use of liquid biopsy & If histology subtype confirms but no adequate tissue for molecular studies \\
Rapid On-site Evaluation (ROSE) & To determine while the procedure is done if the biopsy is adequate \\
Quality assurance & To evaluate the reasons for inadequate biopsy and put plans to address them \\
\hline
\end{tabular}

PET, positron emission tomography.

\section{Acknowledgments}

In collaboration with Arab Collaborative Hematology Oncology Group (ACHOG). Authors acknowledge Ms. Yosra Ali for her data management and Ms. Marie Gretchen Datario for her administrative assistance.

\section{Footnote}

Conflicts of Interest: The authors have no conflicts of interest to declare.

Ethical Statement: The authors are accountable for all aspects of the work in ensuring that questions related to the accuracy or integrity of any part of the work are appropriately investigated and resolved. Approved by the IRB Committee of the King Abdullah International Medical Research Center on January 14, 2014 under the research retrospective study proposal "RC 13/194 - The Study of 
Druggable Molecular Abnormalities in Non-Squamous Non-Small Cell Lung Cancer in the Middle East”.

\section{References}

1. (IARC) IA for R on C. Fact Sheets by Cancer. GLOBOCAN 2012 Estim Cancer Incid Mortal Preval Worldw 2012. 2015. Available online: https://publications. iarc.fr/Databases/Iarc-Cancerbases/GLOBOCAN-2012Estimated-Cancer-Incidence-Mortality-And-PrevalenceWorldwide-In-2012-V1.0-2012

2. Salim EI, Jazieh AR, Moore MA. Lung cancer incidence in the Arab league countries: risk factors and control. Asian Pac J Cancer Prev 2011;12:17-34.

3. Ciuleanu T, Brodowicz T, Zielinski C, et al. Maintenance pemetrexed plus best supportive care versus placebo plus best supportive care for non-small-cell lung cancer: a randomised, double-blind, phase 3 study. Lancet 2009;374:1432-40.

4. Kerr KM. Personalized medicine for lung cancer: new challenges for pathology. Histopathology 2012;60:531-46.

5. Travis WD, Brambilla E, Noguchi M, et al. International association for the study of lung cancer/american thoracic society/european respiratory society international multidisciplinary classification of lung adenocarcinoma. J Thorac Oncol 2011;6:244-85.

6. Pai-Scherf L, Blumenthal GM, Li H, et al. FDA Approval Summary: Pembrolizumab for Treatment of Metastatic Non-Small Cell Lung Cancer: First-Line Therapy and Beyond. Oncologist 2017;22:1392-9.

7. Ofiara LM, Navasakulpong A, Ezer N, et al. The importance of a satisfactory biopsy for the diagnosis of lung cancer in the era of personalized treatment. Curr Oncol 2012;19:S16-23.

8. Yeow KM, Tsay PK, Cheung YC, et al. Factors Affecting Diagnostic Accuracy of CTguided Coaxial Cutting Needle Lung Biopsy: Retrospective Analysis of 631 Procedures. J Vasc Interv Radiol 2003;14:581-8.

9. Zhang Y-C, Zhou Q, Wu Y-L. The emerging roles of NGS-based liquid biopsy in non-small cell lung cancer. J Hematol Oncol 2017;10:167.

10. Bugalho A, Ferreira D, Eberhardt R, et al. Diagnostic value of endobronchial and endoscopic ultrasoundguided fine needle aspiration for accessible lung cancer lesions after non-diagnostic conventional techniques: a prospective study. BMC Cancer 2013;13:130.

11. Verma A, Lim AYH, Tai DYH, et al. Timeliness of Diagnosing Lung Cancer. Medicine (Baltimore) 2015;94:e1216.

12. Priola AM, Priola SM, Cataldi A, et al. Accuracy of CTguided transthoracic needle biopsy of lung lesions: factors affecting diagnostic yield. Radiol Med 2007;112:1142-59.

13. Hsia DW, Jensen KW, Curran-Everett D, et al. Diagnosis of lung nodules with peripheral/radial endobronchial ultrasound-guided transbronchial biopsy. J Bronchology Interv Pulmonol 2012;19:5-11.

14. Yung RCW. Tissue diagnosis of suspected lung cancer: selecting between bronchoscopy, transthoracic needle aspiration, and resectional biopsy. Respir Care Clin N Am 2003;9:51-76.

15. El Saghir NS, El-Asmar N, Hajj C, et al. Survey of utilization of multidisciplinary management tumor boards in Arab countries. Breast 2011;20 Suppl 2:S70-4.

16. El Saghir NS, Keating NL, Carlson RW, et al. Tumor boards: optimizing the structure and improving efficiency of multidisciplinary management of patients with cancer worldwide. Am Soc Clin Oncol Educ Book 2014;34:e461-6.

17. Kehl KL, Landrum MB, Kahn KL, et al. Tumor board participation among physicians caring for patients with lung or colorectal cancer. J Oncol Pract 2015;11:e267-78.

18. van der Heijden EHFM, Casal RF, Trisolini R, et al. Guideline for the Acquisition and Preparation of Conventional and Endobronchial Ultrasound-Guided Transbronchial Needle Aspiration Specimens for the Diagnosis and Molecular Testing of Patients with Known or Suspected Lung Cancer. Respiration 2014;88:500-17.

19. Islam S, Walker RC. Advanced imaging (positron emission tomography and magnetic resonance imaging) and imageguided biopsy in initial staging and monitoring of therapy of lung cancer. Cancer J 2013;19:208.

20. Guo W, Hao B, Chen H, et al. PET/CT-guided percutaneous biopsy of FDG-avid metastatic bone lesions in patients with advanced lung cancer: a safe and effective technique. Eur J Nucl Med Mol Imaging 2017;44:25-32.

21. Werner L, Keller FA, Bhure U, et al. The value of ultrasound-guided biopsy of fluorodeoxy-glucose positron emission tomography (FDG-PET)-positive supraclavicular lymph nodes in patients with suspected lung cancer. BMC Med Imaging 2017;17:41.

22. Jazieh AR, Bounedjar A, Al Dayel F, et al. The Study of Druggable Targets in Nonsquamous Non-Small-Cell Lung Cancer in the Middle East and North Africa. J Immunother Precis Oncol 2019;2:4.

23. Kossakowski CA, Morresi-Hauf A, Schnabel PA, et al. Preparation of cell blocks for lung cancer diagnosis and 
prediction: protocol and experience of a high-volume center. Respiration 2014;87:432-8.

24. Rolfo C, Mack PC, Scagliotti GV, et al. Liquid Biopsy for Advanced Non-Small Cell Lung Cancer (NSCLC): A Statement Paper from the IASLC.J Thorac Oncol 2018;13:1248-68.

25. Ravaioli S, Bravaccini S, Tumedei MM, et al. Easily detectable cytomorphological features to evaluate during ROSE for rapid lung cancer diagnosis: from cytology to histology. Oncotarget 2017;8:11199.

26. Yarmus L, Akulian J, Gilbert C, et al. Optimizing endobronchial ultrasound for molecular analysis. How many passes are needed? Ann Am Thorac Soc 2013;10:636-43.
Cite this article as: Jazieh AR, Bounedjar A, Al Dayel F, Fahem S, Tfayli A, Rasul K, Jaafar H, Jaloudi M, Al Fayea T, Almaghrabi HQ, Bamefleh H, AlKattan K, Larbaoui B, Filalli T, Al Mistiri M, Alhusaini H. Patterns of diagnostic procedures for lung cancer pathology in the Middle East and North Africa. J Thorac Dis 2019;11(12):5162-5168. doi: 10.21037/ jtd.2019.12.03 